Discourse and Communication for Sustainable Education, vol. 12, no. 2, pp. 142-154, 2021

\title{
Integrating Sustainability-Oriented Ecologies of Practice Across the Learning Cycle: Supporting Transformative Behaviours in Transgenerational, Transnational and Transdisciplinary Spaces
}

\author{
Arinola Adefila, Yung Fang Chen, QueAnh Dang and Alun Dewinter \\ Coventry University, Coventry, UK \\ Marta Antonelli and Sonia Massari \\ Barilla Center for Food and Nutrition Foundation, Parma, Italy \\ Annika Saarto \\ University of Turku, Turku, Finland \\ Alessandra Viviani \\ University of Siena, Siena, Italy \\ Tsvetelina Filipova \\ Ricardo Energy and Environment, Oxford, UK \\ Theo Mojitaba Ammari-Allahyari \\ University of Sunderland, London, London, UK \\ Lars Karlsson \\ Consultant PreHAB, Vienna, Austria
}

\begin{abstract}
The article examines the complexities associated with effectively and comprehensively tackling the climate change crisis. Focusing on the need for education, the authors discuss a model of Education for Sustainable Development (ESD) that supports the development of competencies, coalition building and the capacity to support and maintain positive action. Drawing upon principles highlighted by the United Nations, the paper outlines the breadth and depth of knowledge required to support transformative ESD. Firstly enhancing comprehensive knowledge that develops cognitive, affective and axiological dimensions and proficiency. This enhances critical engagement with information and enables individuals to act responsibly and align with others in coalition building. The second element refers to collaborative partnership that is crucial for changes to be effective. This has been one of the most challenging barriers preventing positive action on the catastrophe pf climate change. Finally, the paper emphasizes the need to develop
\end{abstract}


the competencies for supporting collective action, which will enable sustained action across transnational, transdisciplinary and transnational boundaries.

Key words: climate change, collective action, education for sustainable development, sustainability, coalition building

\section{Introduction}

The impetus to act decisively and extensively to achieve the Sustainable Development Goals (SDGs) is increasing as multiple challenges take on a global dimension (Perkins, 2018). Climate change is having a significant impact on the ecology of the planet, as well as economic growth and human wellbeing. Acknowledging the Anthropocene epoch in standardised geological time scale (Philips, 2020) formalises the significance of the role and impact of humans in fostering environmental change at all spatial-temporal scales. The epoch will affect all humanity, obliging an engagement in different temporalities that require newly constituted collectives with layers of political, social, cultural and economic dimensions (Gibson \& Graham, 2015). Failure to reimagine how humans live and engage with the planet will lead to a catastrophe and possibly a different mode of humanity if we survive (Plumwood, 2007).

Several barriers prevent bold and radical solutions that both address problems quickly and comprehensively. From a political perspective, the 2017 Paris Accord initially presented great promise; however, there have been setbacks such as political despondency and a lack of commitment (Nordhaus 2020). Technologically, the slow pace of innovative solutions that are accessible, affordable and sustainable is causing great frustration and discouraging many from participating in the discourse (Moser \& Pike, 2015; Gowdy \& O'Hara, 1997). Disparate communities bifurcating the needs for tackling the climate crisis and facilitating sustainable growth have facilitated the economic dimension of the debate, pitting weak and poor communities against privileged ones (Comolli, 2006). Scholars and activists (Morah, 2019; Reid, 2019) have shown that innovation and awareness raising are important tools for dealing with the threats and transitions to sustainability; however, collective responsibility and community action are most significant in achieving change and the corresponding civic and policy sustainable transformations. Environmental groups and institutions have been developing meaningful ways of engaging citizens at a grassroots level in activities that lead to sustainable behaviours collaborative action. Consequently, it is becoming clear that education (Fedosejeva et al., 2018) and community engagement can help disrupt the multiple barriers and improve knowledge and capabilities, which enhance the urgent need for positive interdependence and collaborative action.

ESD 1 is seen as the promotion of informed, skilled behaviours and ways of thinking, useful in the short-term where the need is clearly identified and agreed.

ESD 2 is seen as building capacity to think critically about what experts say and to test ideas, exploring the dilemmas and contradictions inherent in sustainable living.

Educational institutions are increasingly providing Education for Sustainable Development (ESD) to students; a response to calls by global agencies and activists who 
view sustainability as a global challenge (UNESCO, 2005). Vare and Scott (2007) conceptualise of two types of ESD - ESD 1 and ESD 2.

Providing ESD in formal education settings mixes both ESD 1 and 2 characteristics. Several practical programmes that promote understanding of the environmental crisis and encourage students to act responsibly (Fedosejeva et al., 2018; Suresh et al., 2013). At the primary level, it is common for young people to engage with teaching about the benefits of recycling and discuss how climate change is affecting their neighbourhood. A more robust approach will include an integrated curriculum that equips students with the competencies and graduate attributes to respond to challenges around sustainability. This should incorporate wellbeing and social justice issues, which as the charity Students for Sustainability (2018) suggests contributes to environmental sustainability.

The emphasis in this paper is on a holistic ecology of practice with three distinct dimensions expanded on below. First, a focus on integration of practice, this is essentially about foregrounding practice-based learning that supports systematic reflection. Driven by the process of inquiry, a focus on problem solving local environmental issues and associated complexities is essential (Armstrong, Krasny, \& Schuldt, 2018). Secondly, the paper highlights the need for expertise around Sustainability-Oriented Ecologies. This necessitates the inclusion of a variety stakeholders, such as - researchers, practitioners, activists, business leaders, policy makers and citizens. Attention must be drawn to the need to support everyone to understand the ecological challenges we face on the planet, the complexities involved in seeking viable, sustainable and just solutions (Jasanoff, 2010). Finally, special consideration is given to lifelong learning (Zalasiewicz et al., 2017). This is presented by way of support for cooperation and co-creation in Transgenerational, Transnational and Transdisciplinary spaces. This model supports education that transverses different generations, disciplines and national boundaries, woven into every subject in such a way that enhances citizens competencies and skills to be change agents (Adomssent et al., 2007). ESD 2 helps students to develop the knowledges, skills, values, attributes and competencies that enable them to tackle global challenges with stakeholders and in their communities (UNESCO, 2017). It goes beyond abstract theories and provides opportunities for real world learning.

\section{Communities of Practice (CoPs)}

As community initiatives to limit carbon-heavy behaviours and practices increase, it is important to integrate ESD across the lifelong education spectrum, providing spaces for students and civic society partners to develop knowledge, skills, and attributes together. Environmental education in the community can be developed through local action groups that create alliances - climate change action groups - supporting capacity building and collective social responsibility (Moser \& Pike, 2015). There is an emphasis on business practices and action. However, strengthening ESD and facilitating behaviour change across diverse groups has a lot of potential for long lasting change. Citizens learn and act collaboratively with respect to climate change and sustainability.

Though citizen is a stakeholder in relation to the ecological crisis, key stakeholders in the ESD agenda include researchers, policymakers, practitioners, business leaders and educators. Partnerships that allow groups to discuss shared interest and work collaboratively to develop innovative and transdisciplinary solutions will enable real and contextualised change; enhancing people's lives in the context of their communities 
(Reina, 2019). The key to such a broad collaboration is to provide granularity so that citizens can understand how climate change affects them, provide insights into how the challenges are interlinked across the world and enable local teams to develop suggestions for policy and behavioural change

This kind of integrated ESD is inclusive and practical, allowing for the development of global citizenship competencies across cognitive, affective and axiological dimensions. This transdisciplinary approach employs experts from all arenas to transcend their traditional boundaries and seek integral solutions. Figure 1 shows a framework for developing sustainability via 3Cs: a) understanding and improving competencies, capabilities and capacities for engaging in climate action and sustainable development; b) strengthening coalitions and collaboration networks around sustainable development action through mobilising (lifelong) education initiatives and partnerships; and c) facilitating the development of robust Community Knowledge Networks linked to sustainability.

\section{Figure 1}

\section{Framework for Increasing Sustainability}

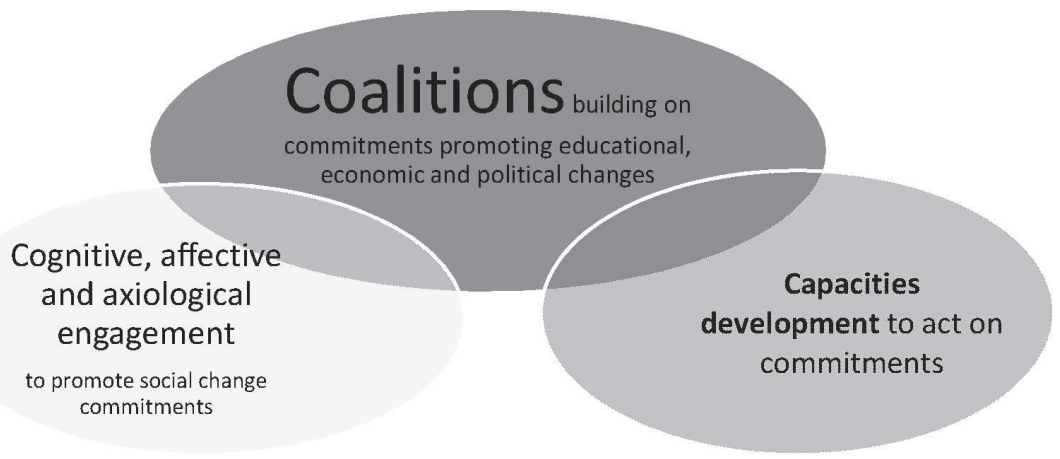

Source: Made by authors.

The community integration is essential because some suggest that morality plays a minor role in leading people to act sustainably (Polzler, 2015). Whilst evolutionary selection may have favoured those with limited perceptions and quick reflexes to deal with sudden threats with the ecological crises, climate change requires exactly the opposite response - an ability to act promptly in order to address the long-term almost imperceptible serious threats to our very survival (Ornstein \& Ehrlich, 2000). We therefore need to incorporate the ways through which political, social, economic and technological dimensions influence climate change, drawing on a range of salient themes and policy areas for both government and civil society.

The role of community partnerships in social and individual wellbeing is vital for sustainability, particularly with respect to addressing inequities and just transitions. An important factor is to be able to provide tools and information that help individual citizens to understand how they contribute and that their collective action actually is worthwhile and makes a difference to what is a global problem. The use of approaches such as the Dutch 'Ecofeedback' where people measure their energy consumption on a very regular basis over time against degree day data whilst taking action to improve 
energy efficiency has re-enforced the benefits of behaviour change to energy consumers in terms of costs and emissions (Staddon et al., 2016). The development of technology is making it easier to inform behaviour at a community scale using an Eco-Feedback approach (Xu et al., 2021)

New approaches focused on co-operation and co-creation can support mutual and lasting change, strengthen relationships amongst stakeholders within local policy ecosystems and enhance opportunities for tangible, evidence-based policy solutions that could have an important and positive impact on local communities and the entire society. For example, White, Habib and Hardisty (2019) have suggested that the use of Social influence, Habit formation, Individual self, Feelings \& Cognition and Tangibility (referred to as SHIFT) can be a useful framework for influencing consumer behaviour towards sustainable consumption.

\section{Knowledge Networks}

A number of organisational and political factors have been seen to contribute to the success of sustainability indicators to effect behavioural change at the community level, be it at a city or a neighbourhood level (Dluhy \& Swartz, 2006). Communities of practice co-design and co-produce sustainability through learning and action. Ideas and resources are shared and this integration provides authentic behaviour change and civic action in communities. CoPs emphasizes networking and innovation, these tools are particularly relevant in communicating the climate crisis, mobilising action and sustaining transformative partnerships. Knowledge, competent action and collaborative working (Waterschoot, 2020) drive innovation. An intergenerational CoP which community young people, university students and community organisations (activists, businesses, social entrepreneurs, local government networks, non-governmental organisations). This represents a cross section of stakeholders and community actors. We include first order activities that focus on educating, collaborative discussions and team working because of the need to ensure that the next generation is adequately, informed, prepared and capable of resourcing and leveraging the right tools in tackling the climate crisis. We include age-specific activities, which enable young people to understand the climate crisis and collaboratively explore solutions with older generations.

Universities could be used as anchor institutions. Focusing on mobilising stakeholders of varying community segments (youth, civic society organisations, technical experts and government networks) collaboratively learn to leverage political and expert networks in order to take local action with respect to the climate crisis. These will be designed to mobilise and develop transgenerational, transdisciplinary and transformative communities of practice and engagement of community groups.

It is important that universities become green as they contribute significantly to carbon intensive activities - such as travel for academic conferences, inefficient buildings and poor urban design flows for large communities of students (Sharp, 2002). The incentives for action in universities is still considerably small. Universities win awards for working independently and consideration is not paid to how their actions may cancel out efficiencies. Universities do not always collaborate with their local communities. Yet, a precedent for linking the practicality of the city with the knowledge and science of the university can be found in "urban-style milieus that pose either an alternative to 
the university or a complementary partner," e.g., incubators and industrial campuses. Thomas Bender (1988) argues these two worlds can be bridged with conversations between a range of academic groupings on the campus - researchers involved in examining the sociocultural, technological, political and economic implication of environmental justice and sustainable ecologies in the Anthropocene, policy makers, student groups etc. and a wide range of constituencies in the metropolis. Columbia University in the US is a good example of a university that has well-established links with various learned societies: botanical gardens, museums, religious groups, regulatory bodies, professional societies, trade unions, schools and community associations. These networks bend the university towards different kinds of missions and there is a mutual economic and political benefit (Asheim \& Isaksen, 2002).

This approach goes beyond changes within the university, also engaging the whole ecosystem around the university to mobilise and create solutions that support all stakeholders in one form or another. University, community and regional coalitions promise wider reach and longer lasting effects. The university can play a European level role by collaborating in green consumption and production in various spheres. The aim will be to mobilise strategic interventions. These are Innovative way of utilising interventions to link deliberative processes like study circles and organising campaigns involving community mobilisation (Rusch \& Swarts, 2015). The strategic intervention can play several key roles in promoting green universities and communities by addressing various potential barriers to action and social change.

\section{Dimensions of Engagement - All Stakeholders}

One key area for ensuring transformative behaviours is enabling communities to understand and define what sustainability means in practice and how it could be measured in a way, which is meaningful to the populace and could stimulate action for change at the community and institutional level (Mischen et al., 2019). As such a broad coalition of stakeholders and inclusive practice is needed to drive engagement by explore how community stakeholders engage with the knowledge exchange process and ways through which knowledge is democratised. Co-production within communities is critical to develop shared resources to address local challenges. The overall aim will be to integrate theories of social learning and collective action, to enhance the work of sustainability practitioners and provide drivers for change. Here the concept of collective action is as a practical tool. It is believed that social learning and collective action competence can reinforce voluntary sustainability initiatives and practices. The term "collective action competence" is derived from Clark et al. (2016), is adapted by the UNESCO (2017) and defines the capability of a group of people to direct their behaviour toward a common goal based on a collectively developed literacy, competences, and needs or goals. The term "collective action competence" can be seen as a novel unifying concept articulating a critical capability needed for collective behaviour change in social settings such as HEIs (Boreham, 2004). Collective action competence is based on theories of classical collective action but it is also supported by the "activity theory" developed by Vygotsky (1978). 


\section{Figure 2}

Monitoring of Sustainability Transformation

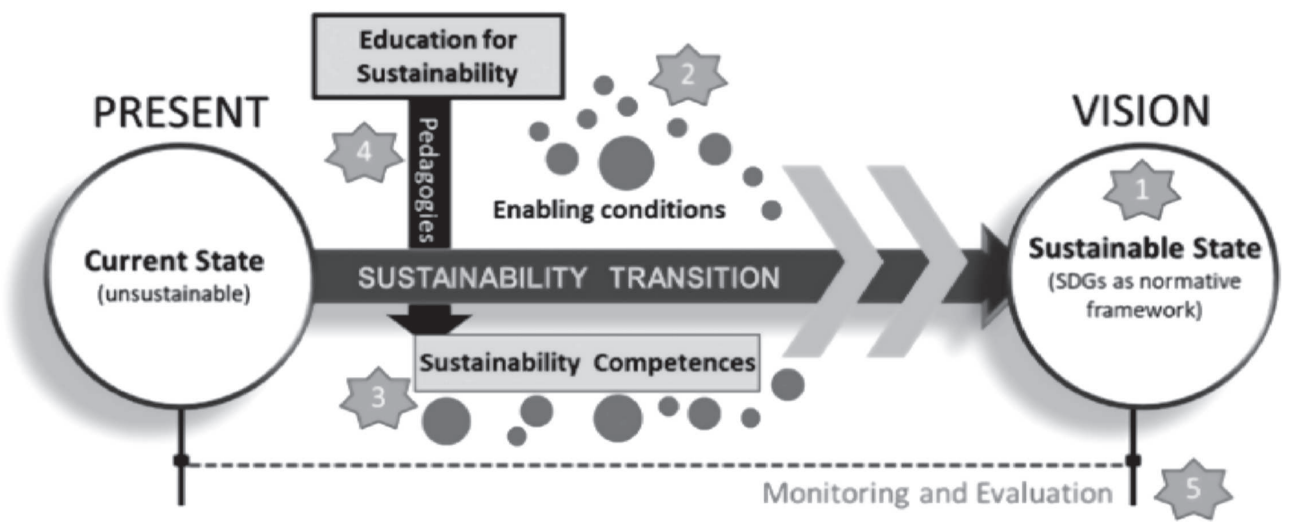

Source: Made by authors.

Using a design thinking approach, which brings together students, academics, professional practitioners, community activists, social entrepreneurs and business leaders across a broad range of disciplines and interests people, can be enthused with creative confidence to design new solutions to complex issues affecting sustainable futures. (Kelly, 2016; Kelly, 1998). CoPs are able to act efficiently at a local level. They have the resources and leverage to be efficient, responsive and inspirational. CoPs can examine and map the socialisation processes sustaining cycles of indifference, ecological guilt and climate anxiety in various communities using ecological analysis both at individual and institutional levels (formal, informal, non-formal and community learning spaces, and then enhance action through the process of incubating change agency in communities of practice). For example, Civil Society Organisations can have a broad influence - such as providing accessible education via community activities to targeted groups, especially young people, mobilising action or lobbying local politicians to act.

Stakeholders work collaboratively to co-create and develop effective solutions, analyse key issues around Climate Change communication and the related politics and dynamic realities that have inspired or inhibited active action around climate change and sustainability. CoPs bring transdisciplinary expertise, research and practice networks supporting reflection that produces a more nuanced view of local mind-sets, incentive structures and social and behavioural change mechanisms, including enabling as well as inhibiting factors for various segments of society. In addition, it is possible to leverage the transdisciplinary expertise as a means of employing a range of methodologies, technologies and approaches. Scenario workshops can be used to support the groups' practical action and strategic decision-making. The transdisciplinary, transgenerational and transnational teams and communities could engage with topics of interest linked such as Food, Recycling and Reusing, Consumerisation \& Waste, Responsive \& Ethical Manufacturing etc.

These types of approaches invariably support transgenerational, transnational and transdisciplinary solidarity enhancing effective and inclusive action on the social and behavioural aspects of climate change action. Ensure communities coalesce around local 
Green Deal related issues and through the lens of transdisciplinary research that integrates historical, cultural, societal, economic and psychological perspectives educate, inspire and seek solutions. Improved management, inter alia, of the uncertainty derived from climate change through bottom-up approaches. Furthermore, there are opportunities to produce bespoke resources and case studies, activity templates that can support both individual and collective action among citizens, communities, businesses, workplace, decision makers and institutional actors. In the long term, systemic change at the level of political and economic structures, culture and society and contribution to one or several of the Sustainable Development Goals.

\section{Learning Spaces for Integrating the Transgenerational, Transdisciplinary and Transnational}

We need action that would develop participants' capacities, paying special attention to integrating cognitive, affective and axiological dimensions learning. It is possible to achieve this through deploying systems thinking, social change-oriented education, playful approaches and transdisciplinary knowledge and collaborative action. Peer learning and continuous lifelong learning facilitated by practical engagement (Kohl \& Hopkins, 2020) are essential for transformation of behaviours. Technological innovation has provided powerful tools for enabling learning across generations. It is possible to envisage a number of resources such as environmental games, discussion forums, cooperatives being used to bridge the gap between universalised science/facts/bodies of knowledge and local meaning-making contexts. However, individual or collective understanding can be interpreted and acted upon in different ways, based on cognitive, affective or axiological dimensions of learning (Rekalde-Rodríguez, Gil-Molina, \& Cruz-Iglesias, 2021); facilitated cooperation on CoPs across the transgenerational, transdisciplinary and transnational (3Ts) can bring about a new learning culture, which is not necessarily academic but participatory.

Co-production embeds linkages between multiple stakeholders including experts, innovators, designers, students, policy makers and users. Participants can interrogate regional challenges and resources that are place-specific and involve contextual knowledge, and tacit knowledge, through collaborative learning. While attention to the global scale is important, global standards can undermine "attention to the local knowledge" that is "necessary for implementing ... global rules effectively in particular contexts" (Clark, van Kerrhoff, \& Gilberto, 2016).

The need to integrate collective action and decision making in postmodern life is becoming evident. Urban life, in many places is highly dynamic and digitalisation is increasingly framing social interactions. This is contributing to estrangement, particularly of younger generations who do not always have access to the spaces and tools to develop social relationships require cooperation, communication, trust and shared rules built and established collectively over long periods (Lobao \& Stofferahn, 2008). There is a need for new and systematic approaches to train and support individual and collective decision-making. Formal education and socialisation processes are typically the means of acquiring the societal learning for sustainability transformations, especially around common pool resources or public goods shared between two or more actors, such as ponds, trees or grass. Reckless use of the resources diminishes the commons, yet it is difficult to limit inconsiderate actors' access (Ostrom, 2020). 
The commons system involves rules governing the use and maintenance of a shared resource, e.g. fisheries, agricultural water and land resource systems and collectively managed forests, etc. We can see the emergence of newly emerging commons such as organisation of urban gardens, coordination of transportation systems and maintenance of common urban space. Decision making in one community has knock-on effects on traditional supply chains of goods and services, and global commons such as climate and biodiversity; both political and biophysical processes taking place in multiple commons affect everyone. Regardless of the form, sustainable governance of commons in an urban context in particular requires understanding and engagement at the grassroots levels supported by higher-level authorities.

The educational system has not been able to equip global citizens effectively to make ecologically sound decisions. Educational systems are also fractured by socio-political and geographic distancing, which make cooperation even more challenging. Effective ESD for the education space is therefore essential. Integrating not only ESD 1 and 2 as mentioned above, but also bringing together a range of communities. Learning in this case is focussed on the development of competencies and skills, which actually lead to individual and collective behaviour transformation.

The word "Gestaltungskompetenz" is used in Germany to describe a means of operationalising successful ESD. "Gestaltungskompetenz" defined by de Hann and Harenberg $(1999$, p. 62) as "forward-looking ability to modify and to shape the futures of those societies we live in via active participation in terms of a sustainable development" is focused in activism, reflexivity, co-operative participation toward sustainable development. Outlining eight key competencies, de Haan (2006, pp. 22-25) shows the necessity for all citizens to work in solidarity to tackle the climate crisis in a just and ethical manner.

- Foresighted thinking;

- Interdisciplinary work;

- Cosmopolitan perception, transcultural understanding and co-operation;

- Participatory skills;

- Planning and implementation;

- Capacity for empathy, compassion and solidarity;

- Self-motivation and in motivating others;

- Distanced reflection on individual and cultural models.

The need for consistent, coordinated action and changes to infrastructure supporting positive change is affirmed through the entire learning cycle, this also invariably spills into all aspects of psychosocial, economic life (Kohl \& Hopkins, 2020).

\section{Conclusions}

In order to effectively tackle the climate crises and ensure an ethical, just transition to sustainable living, it is important to integrate sustainability-oriented ecologies of practice into communities. On the one hand, this requires ESD that enhances both short and long-term objectives weaving in into formal curricula and seeking social learning approaches to enhancing transformative behaviours in transgenerational, transnational and transdisciplinary spaces. Social learning raises consciousness about long-term ecological challenges and supports participation in communities, helping locals to identify, understand, discuss and visualise consequences of taking different actions. At the same time, it is important to provide complementary skills for coalition building and explore 
solutions to local challenges in real time. This paradigm shift enables the democratising of environmental decision-making and supports capabilities and capacity to make decision about public goods and resources on a local and interlinking global dimension.

There is a further need to unpack complexities around how sustainability policies affect the poor and vulnerable. This is rooted in histories of inequalities, which have not sufficiently provided effective practical ESD across communities. Educational and organising projects informed by a theoretical understanding and diagnosis of problems linking diverse constituencies that address climate and ecological problems have to consider intersectional challenges and understand systemic and structural components of environmental justice. For example looking at how the city of Seattle integrates housing, environmental, wellbeing and health challenges. It is important to prioritise novel opportunities for collective action, interactive, democratic consultation or integrative innovative solutions (associated with green technology, jobs, entrepreneurship, and linking producers and users).

\section{References}

Adomssent, M., Godemann, J., Michelsen, G., Barth, M., Rieckmann, M., \& Stoltenberg, U. (2007). Developing key competencies for sustainable development in higher education. International Journal of Sustainability in Higher Education, 8(4), 416430. https://doi.org/10.1108/14676370710823582

Armstrong, A. K., Krasny, M. E., \& Schuldt, J. P. (2018). Communicating climate change: A guide for educators. Place: Comstock Publishing Associates.

Asheim, B. T., \& Isaksen, A. (2002). Regional innovation systems: The integration of local 'Sticky' and Global 'Ubiquitous' Knowledge. Journal of Technology Transfer, 27(1), 77-86.

Bender, T. (1988). The university and the city: From medieval origins to the present. Oxford: Oxford University Press on Demand.

Boreham, N. (2004). A theory of collective competence: Challenging the neo-liberal individualisation of performance at work. British Journal of Educational Studies, 52(1), 5-17. doi: 10.1111/j.1467-8527.2004.00251.x

Clark, W. C., van Kerkhoff, L., Lebel, L., \& Gallopin, G. C. (2016). Crafting usable knowledge for sustainable development. PNAS, 113(7), 4570-4578.

Comolli, P. (2006). Sustainability and growth when manufactured capital and natural capital are not Substitutable. Ecological Economics, 60(1), 157-167. doi.org/ 10.1016/j.ecolecon.2005.11.018.

de Haan, G. (2006). The BLK '21' programme in Germany: a 'Gestaltungskompetenz'based model for education for sustainable development. Environmental Education Research, 119-132.

de Haan, G., \& Harenberg, D. (1999). Gutachten zum Programm Bildung für eine nachhaltige Entwicklung, Materialien zur Bildungsplanung und zur Forschungsförderung, Heft 72, Bund-Länder-Kommission für Bildungsplanung und Forschungsförderung, Bonn [Expert opinions on the education for sustainable development program, materials for educational planning and research funding], 72, Federal State Commission for Educational Planning and Research Funding, Bonn.

Dluhy, M., \& Swartz, N. (2006). Connecting knowledge and policy: The promise of community indicators in the United States. Social Indicators research, 79, 1-23. 
Fedosejeva, J., Boče, A., Romanova, M., Iliško, Dz., \& Ivanova, O. (2018) Education for sustainable development: The choice of pedagogical approaches and methods for the implementation of Pedagogical Tasks in the Anthropocene Age. Journal of Teacher Education for Sustainability, 0(1), 157-179. https://doi.org/10.2478/jtes2018-0010

Gibson-Graham, J. (2015). Ethical economic and ecological engagements in real(ity) time: Experiments with living differently in the Anthropocene. Conjunctions. Transdisciplinary Journal of Cultural Participation, 2(1), 44-71. https://doi.org/ 10.7146/tjcp.v2i1.22270

Gowdy, J., \& O'Hara, S. (1997). Weak sustainability and viable technologies. Ecological Economics, 22(3), 239-247. https://doi.org/10.1016/S0921-8009(97)00093-1

Suresh, J., Aggarwal, P., Sharma, N., \& Sharma, P. (2013). Fostering sustainability through education, research and practice: A case study of TERI university. Journal of Cleaner Production, 61, 20-24.

Jasanoff, S. (2010). A new climate for society. Theory, Culture \& Society, 27(2-3), 233-253.

Kelly, R. (2016). Creative development: Transforming education through design thinking, innovation and invention. UK: Brush Education.

Kelly, K. L. (1998). A systems approach to identifying decisive information for sustainable development. European Journal of Operational Research, 109(2), 452-464.

Kohl, K., \& Hopkins, C. A. (2020). ESD for all: Learnings from the \#Indigenous ESD Global Research. Journal of Teacher Education for Sustainability, 21(2), 105120. https://doi.org/10.2478/jtes-2019-0020

Lobao, L., \& Stofferahn, C. W. (2008). The community effects of industrialized farming: Social science research and challenges to corporate farming laws. Agriculture and Human Values, 25(2), 219-240.

Mischen, P., Homsy, G., Lipo, C., Holahan, R., Imbruce, V., Pape, A., Zhu, W., Graney, J., Zhang, Z., Holmes, L., \& Morath, S. (2019). Individual action, collective change: Six ways individuals can create Environmental Change. Harvard Law \& Policy Review Online. University of Houston Law Center No. 2019-A-10.

Mischen, P. A., Homsy, G. C., Lipo, C. P., Holahan, R., Imbruce, V., Pape, A., Zhu, W., Graney, J., Zhang, Z., Holmes, L. M., \& Reina, M. (2019). A foundation for measuring community sustainability. Sustainability, 11(7), 1903. 1-16.

Moser, S. C. (2016). Never too old to care: Reaching an untapped cohort of climate action champions. Public Policy \& Aging Report. doi: 10.1093/paper/prw029

Moser, S. C., \& Pike, C. (2015). Community engagement on adaptation: Meeting a growing capacity need. Urban Climate, 14(1), 111-115.

Nordhaus, W. (2020). The climate club: How to fix a failing global effort. Foreign Affairs, 99, 10.

Perkins, P. E. (2018). Climate justice, gender and intersectionality. In T. Jaffry (Ed.), Routledge Handbook of Climate Justice (pp. 349-358). New York, NY: Routledge.

Ornstein, R., \& Ehrlich, R. (2000). New world new mind: Moving toward conscious evolution. Los Altos, CA: ISHK publising.

Ostrom, E. (1990). Governing the commons: The evolution of institutions for collective action. UK: Cambridge University Press. 
Phillips, J. (2020). The sustainability dynamics framework - a holistic approach to define and evaluate sustainability and unsustainability in the Anthropocene. Environmental Impact Assessment Review, 84, 106-136. https://doi.org/10.1016/j.eiar. 2020.106436

Plumwood, V. (2007). A review of Deborah Bird Rose's reports from a wild country: Ethics of decolonisation. Australian Humanities Review, 42, 1-4.

Polzler, T. (2015). Climate change inaction and moral nihilism. Ethics, Policy \& Environment, 18(2), 202-214.

Reid, A. (2019) Climate change education and research: Possibilities and potentials versus problems and perils? Environmental Education Research, 25(6), 767-790. doi: 10.1080/13504622.2019.1664075

Rekalde-Rodríguez, I., Gil-Molina, P., \& Cruz-Iglesias, E. (2021). The IraunIK and IraunIR questionnaires: Assessment of transversal competencies for sustainability. Journal of Teacher Education for Sustainability, 23(1), 22-40.

Rusch, L., \& Swarts, H. (2015). Practices of engagement: Comparing and integrating deliberation and organizing. Journal of Community Practice, 23(1), 5-26.

Sharp, L. (2002). Green campuses: The road from little victories to systemic transformation. International Journal of Sustainability in Higher Education, 3(2), 128-145.

Staddon, S., Cycil, C., Goulden, M., Leygue, C., \& Spence, A. (2016). Intervening to change behaviour and save energy in the workplace: A systematic review of available evidence. Journal Energy Research \& Social Science, 17, 30-51.

United Nations Decade of Education for Sustainable Development 2005-2014: The DESD at a glance. Paris: UNESCO.

United Nations Educational, Scientific and Cultural Organization (UNESCO). (2017). Education for sustainable development goals: Learning objectives. UNESCO, Paris, France.

Van Kerkhoff, L. E., \& Lebel, L. (2015). Guest editorial: Co-productive capacities: Rethinking science-governance relations in a diverse world. Ecology and Society, 20(1), 1-6.

Vare, P., \& Scott, W. (2007). Learning for a change: Exploring the relationship between education and sustainable development. Journal of Education for Sustainable Development, 1(2), 191-198. https://doi.org/10.1177/097340820700100209

Vygotsky, L. S. (1978). Mind in society: The development of higher psychological processes. (M. Cole, V. John-Steiner, S. Scribner, \& E. Souberman (Eds.).) Cambridge, Massachusetts: Harvard University Press.

Waterschoot, S. E. (2020). Director for youth, education and Erasmus+ at the European Commission, CIVIS online conference, education for a sustainable future. Stocholm: Stockholm University, Stockholm, 1-5.

White, K., Habib, R., \& Hardisty, D. (2019). How to SHIFT consumer behaviors to be more sustainable: A literature review and guiding framework. Journal of Marketing, l83(3), 22-49.

Xu, L., Francisco, A., Taylor, J. E., \& Mohammadi, N. (2021). Urban energy data visualization and management: Evaluating community-scale eco-feedback approaches. Journal of Management in Engineering, 37(2), 20111-20125. 
Zalasiewicz, J., Waters, C. N., Summerhayes, C. P., Wolfe, A. P., Barnosky, A. D., Cearreta, A., Crutzen, P., Ellis, E., Fairchild, I. J., Gałuszka, A., Haff, P., Hajdas, I., Head, M. J., Ivar do Sul, J. A., Jeandel, C., Leinfelder, R., McNeill, J. R., Neal, C., Odada, E., Oreskes, N., Steffen, W., Syvitski, J., Vidas, D., Wagreich, M., \& Williams, M. (2017). The Working Group on the Anthropocene: Summary of evidence and interim recommendations. Anthropocene, 19, 55-60. https://doi.org/ 10.1016/j.ancene.2017.09.001

Correspondence concerning this paper should be addressed to Doctor Arinola Adefila, the Centre for Global Learning at Coventry University. Email: Arinola.Adefila@coventry.ac.uk 